\title{
THE DESERT ROSE DOMES OF THE SOUF REGION (ALGERIA). PRELIMINARY EVALUATIONS ON THE VULNERABILITY OF A UNIQUE VERNACULAR HERITAGE
}

\author{
C.Azil ${ }^{1,2, *}$, L. Rovero $^{2}$, B. Djebri ${ }^{1}$, F. Fratini ${ }^{3}$, G. Misseri ${ }^{2}$, U. Tonietti ${ }^{2}$ \\ ${ }^{1}$ LVAP, Laboratoire Ville, architecture et patrimoine, Ecole polytechnique d'architecture et d'urbanisme EPAU, \\ Alger, Algeria - (c.azil, B.Djebri)@epau-alger.edu.dz \\ ${ }^{2}$ Dept. of Architecture, University of Florence, Florence, Italy - (chima.azil, luisa.rovero, Giulia.misseri)@ unifi.it \\ ${ }^{3}$ Institute of Heritage Science- National Research Council, Florence, Italy - fratini@icvbc.cnr.it
}

\section{Comission II - WG II/8}

KEYWORDS: Gypsum desert rose, Domed settlements weaknesses, Materials characterization, Building culture

\begin{abstract}
:
The vernacular architecture of the Souf region in Algeria, a desert environment where wood is rare, presents multiple heritage values due to the way in which local materials (especially the desert rose stone) are exploited to build houses and erect distinctive domes. Unfortunately, extensive damage and abandonment compromise the stability of these buildings and accelerate their disappearance, which would negatively affect the urban landscape and the identity of the region. In order to safeguard this unique vernacular heritage, the study focuses on the definition of the typical typology of building, its structural and geometric characteristics, explaining the constructive technique used. Recurrent damage and pathologies that threaten this building culture are also highlighted. Then, estimation of mechanical parameters of the desert rose stone masonry is carried out defining typical characteristics according to the evaluation of the respect of "the rule of the art". Results are then used to perform numerical simulations of the structural behaviour of a typical building, through the finite element method with linear and nonlinear approaches. In particular, the structural behaviour of the dome has been investigated, being the most vulnerable element of the system.
\end{abstract}

\section{INTRODUCTION}

The vernacular buildings made of local material - 'Desert Rose' stone - which typify the Souf Oases in the East of Algerian desert, represent architecture typology, integrated harmoniously in a hard desert environment, from the 16th century. These Oases represent a Cultural Heritage of important values, consequently, it is included in the "Tentative List of UNESCO 2002". The most distinctive characteristic of the Souf Oasis architecture is the extensive presentence of domes, used as roofs in all buildings. These domes participate to improve the interior thermal comfort, and to draw a unique urban landscape. The Souf vernacular architecture symbolises a special identity element of the Cultural Heritage of the Souf region, and as such, they need to be protected and handed down to the following generations (Figure 1).

The building technique is based on irregular blocks of 'Desert Rose' stone and gypsum mortar joints, with mineralogical composition similar to the blocks. The typical vernacular building is constituted of several simple domed units, organised around a courtyard.

Such vernacular architecture heritage is endangered by continuing processes of abandonment and renovation through incompatible interventions, or demolition and replacement with modern building techniques badly implemented, similarly to what happens in many other contexts (Rovero, Fratini 2013; Baglioni et al., 2016a, 2016b).

Thus, field and laboratory investigations are fundamental to reach adequate knowledge of this constructive culture, to define the nature of pathologies and recurrent damages, and to understand the structural system. (Almeida et al., 2012; Rovero et al., 2009; Rovero, Fratini 2013; Baglioni et al., 2016a, 2016b; Boostani et al., 2018; Liberotti et al., 2016; Rovero and Tonietti 2012; Sani et al., 2012; Rovero et al., 2016; Almeida et al., 2012; Briccoli Bati 2001)

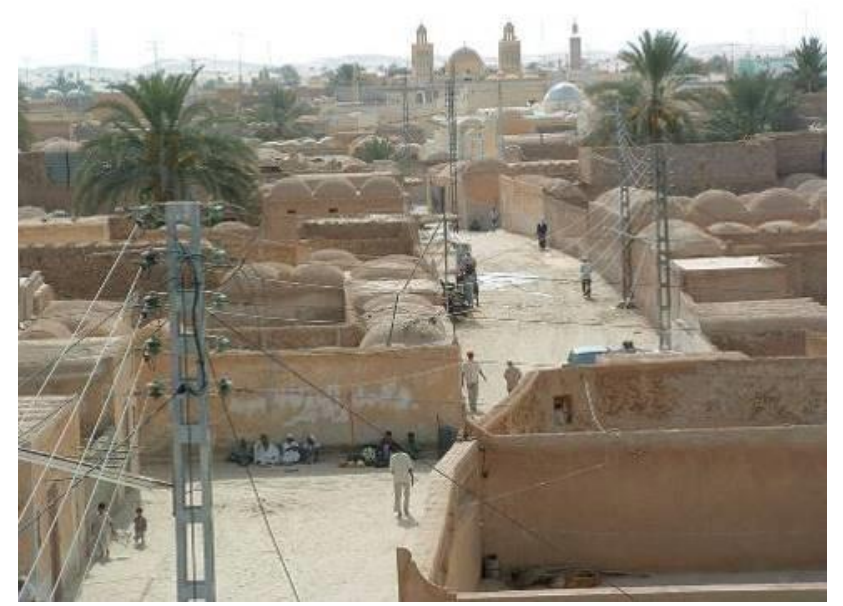

Figure 1. Landscape of Guemar city, Souf.

The paper is organised in four chapters. The second chapter reports on the emergency factors of the Souf architectural typology and the geometric, constructive and mechanical characteristics of 'Desert Rose' masonry. Chapter three examines the structural behaviour of a representative dome through linear and nonlinear FEM analyses.

\footnotetext{
* Corresponding author
} 


\section{THE SOUF CONSTRUCTIVE CULTURE}

\subsection{Emergency factors of the Souf architectural typology}

Vernacular landscape and architecture of the Souf region is inherently originated from the combined work of nature and humans. The use of domes is connected to the environmental context, i.e. the desert environment, where the lack of wood, has prevented the use of flat roofs in all the region. In addition, the development of this architectural typology is due to geological resources, where several peculiar materials are locally available (Cote, 2006; Cote, 2005). The section of geological layers shows the diversity of rocks in Figure 2 (Bataillon, 1955). The rocks that are frequently used in the construction are: 'Desert Rose' stone called locally 'Louz', and 'Tafza' stone (Figure 3) in additional to the 'Salsa' stone, which is relatively less used.

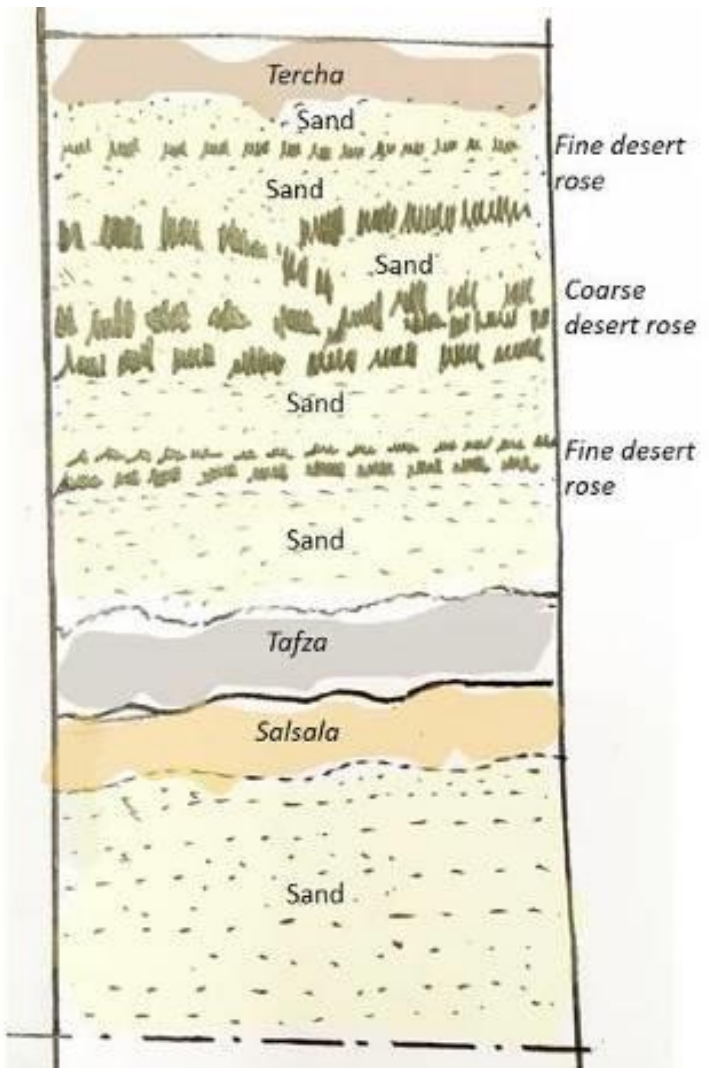

Figure 2. Schematic geological section in the Souf region.
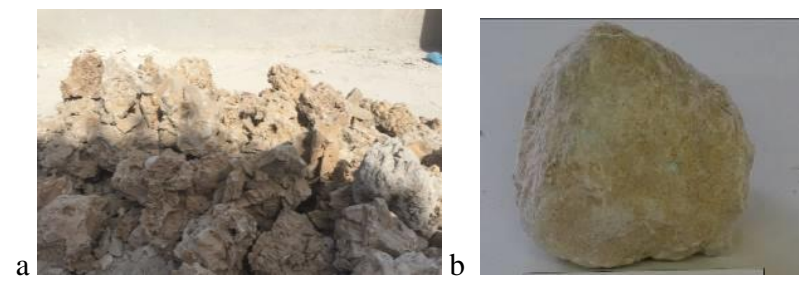

Figure 3. a. 'Desert Rose' stone. b. Tafza stone.

Each material undergoes a process of transformation and preparation before being used in construction. The principal building material, the 'Desert Rose' stone, constituted of gypsum solidification, is found in layers and in the shape of big blocks (Azil et al., 2018; Azil et el., 2019). The extraction is carried out with different tools such as the plier, the pickaxe and sometimes dynamite. This stone is used in the form of coarse rubbles, with an irregular shape and various dimensions, for the construction of foundations, walls and domes (Lebsir, 2016). Secondly, the 'Tafza' stone, which is a hard, white stone, constitutes the raw material to obtain gypsum binder used for bedding mortar and for plastering. In order to obtain the gypsum powder, the 'Tafza' stone is extracted from deepest layers off the ground. Then, following the period of drying (due to the contact of the stone with the water table), stones are reduced in little blocks. After that, the blocks are burned in a furnace for two hours with temperature ranging from $110^{\circ}$ to $200^{\circ}$ Celcius (Figure 4). After this step, two days are necessary to 'Tafza' in order to cool down. In the end, burned 'Tafza' blocks are reduced into powder, and during this operation, some wooden ash accidentally mixes with gypsum powder as is shown in figure 5 (Azil et al., 2018). Concerning the 'Salsa' stone, this is used, in some cases, for foundations.

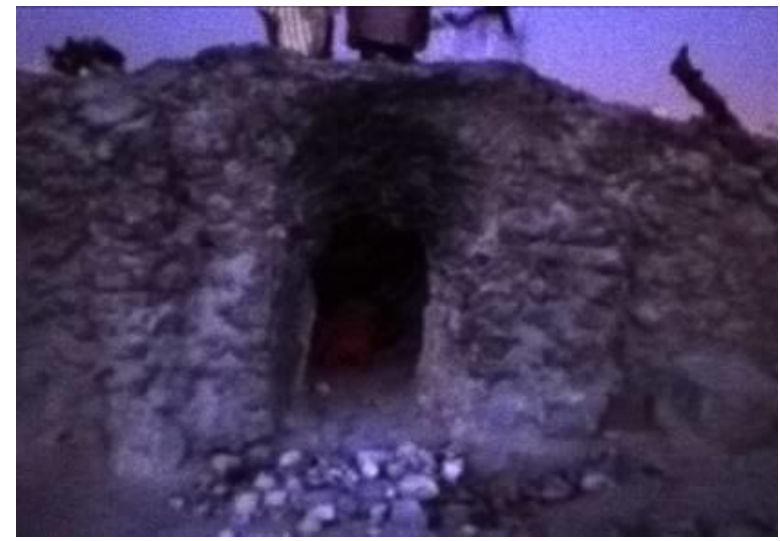

Figure 4. Traditional Furnace of Gypsum.

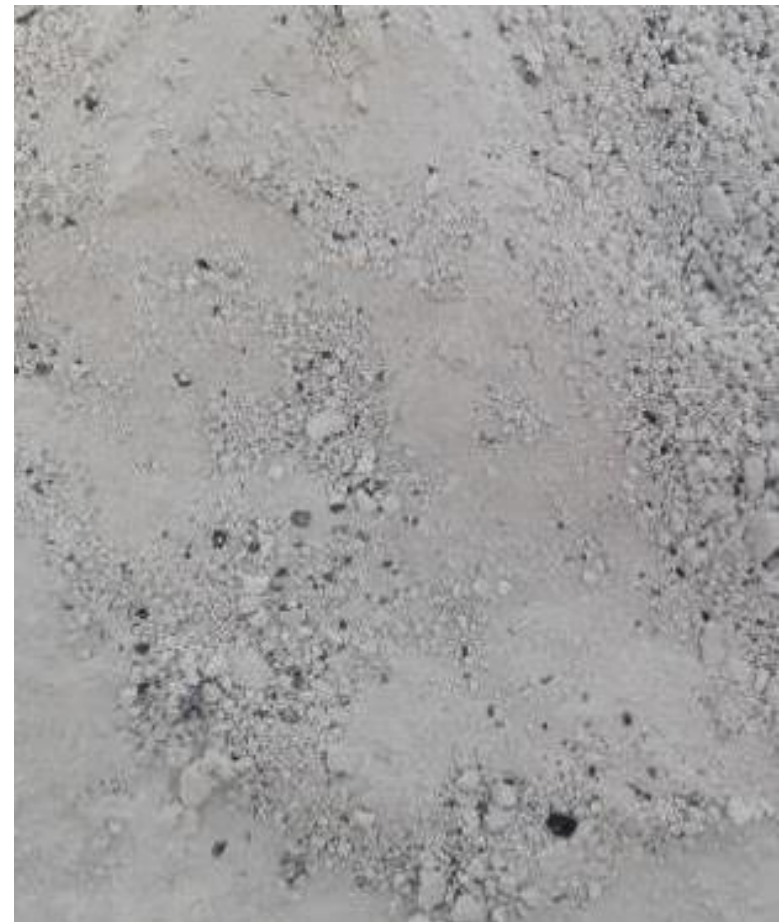

Figure 5. Gypsum powder with wooden ash.

The extraction process described before is facilitated by the typical cultivation technique of the region; thus, it represents again a perfect balance between human needs and landscape management. Indeed, the region is known for the so called 'Ghitanes' (Figure 6), which are micro-oases made by habitants 
to implement peculiar technique of cultivation. Basically, the area for cultivation is created by digging the dunes in order to reach the water table. During this process, the blocks of rocks are extracted, and used as building materials in the buildings.

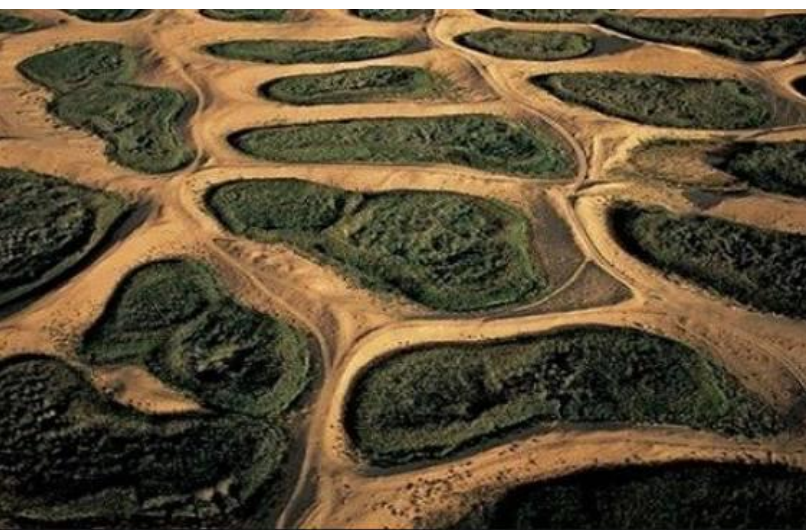

Figure 6. 'Ghitanes' cultivation technique,

https://dzcharikati.net/el-oued-la-phoeniciculture-dans-le-ghoutun-patrimoine-agricole-et-touristique/, accesses on 20/01/2020.

\subsection{Constructive and geometric features}

Various investigations in situ have been conducted in order to identify common rules of the constructive technique and the geometry of minor and major buildings. The typical minor building, the house, has an introverted organisation around a square or rectangular courtyard, which is surrounded by domed units constituting the perimeter of the house (Figure 7). The domed unit is approximately a square, and its dimension is around $2.5 \mathrm{~m}$. The domed unit can be single or double, and, in this second case, the two volumes are connected by an arched passage.

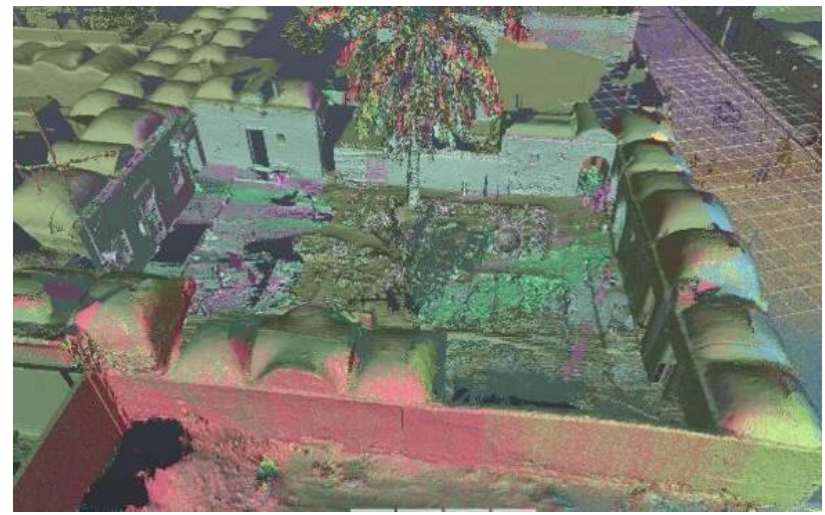

Figure 7. 3D survey of a typical minor building courtyard.

\subsubsection{Foundations and walls}

Foundations could be made of Salsa stone or the big blocks of 'Desert Rose' stone, but this latter is the most common, which are used wich bedding mortar consists of gypsum obtained from burning of Tafza stone. To erect masonry portions, the quantity of gypsum mortar is remarkable compared to the amount of 'Desert Rose' blocks, roughly around one-to-one ratio because of the irregularity of the blocks. Foundations depth ranges from 50 to $70 \mathrm{~cm}$ and thickness is between 40 and $45 \mathrm{~cm}$. Rising from foundations, walls are slightly less thick. Generally, walls show one or two leaves made of medium-sized blocks; to fill the gaps, smaller stones are introduced. Due to the irregularity of the blocks shape, the texture of the walls is very irregular; therefore, the walls are plastered with a gypsum-based rough-coating. To this aim, the burned and crushed 'Tafza' stone is employed, after being sifted in order to eliminate the big pieces of wooden ash and to have smooth surface. The thickness of gypsum plastering for inside walls varies according the quantity needed in order to smoothen the surface. Generally, the plaster layer employed for outside walls is thicker, ranging from 5 to $10 \mathrm{~cm}$. At the end, wall thickness varies between 30 and $35 \mathrm{~cm}$ in the minor building. After the construction is finished, it is difficult to distinguish the masonry texture, the blocks from the gypsum mortar because the wall appears like a sort of conglomerate (Figure 8).
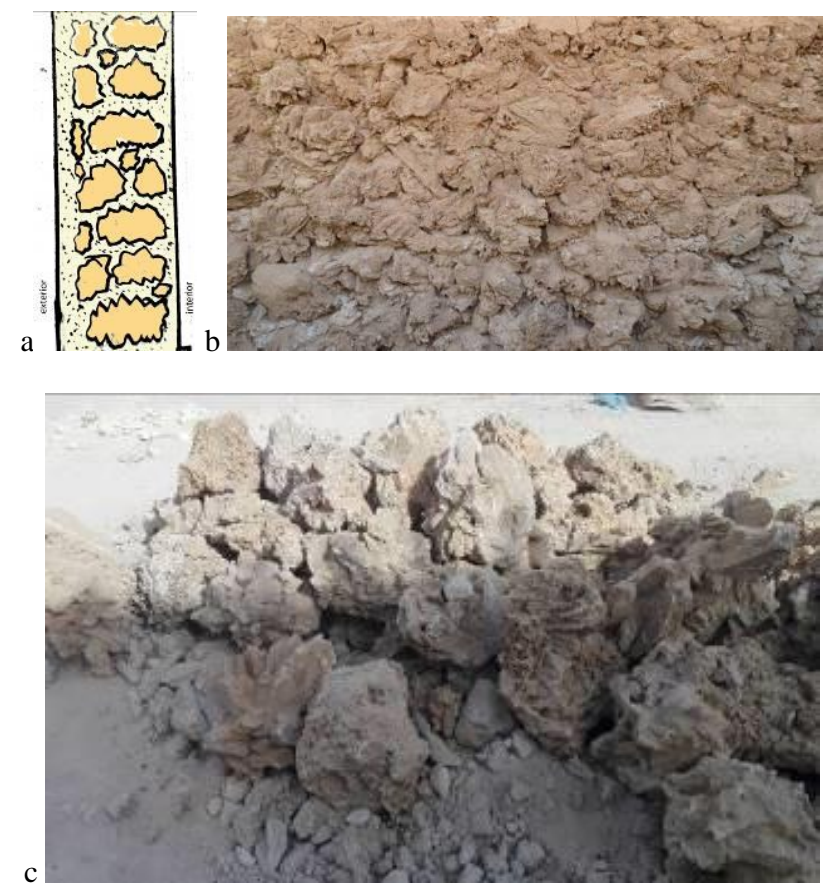

Figure 8. a. Section of 'Desert Rose' stone masonry. b. Wall of masonry building. c. Big 'Desert Rose' blocks.

\subsubsection{Arches and domes}

An arch, which is added between two single units, allows to join volumes of them and widen the space (Figure 9.a). The arch rings, average thickness of $15 \mathrm{~cm}$, are built without centring and employing 'Desert Rose' blocks placed with roughly a radial texture and gypsum bedding mortar (Figure 9.b). Arches are also used in the gallery of courtyard (Figure 9.c).

Regarding the domes, to regularise transition between the circular shape of the shell and the square shape defined by the walls, squinches are placed at corners. Concerning masonry execution for domes, which is realised without centring owing to the rapid setting of the gypsum, it raises from the square shape and grows in successive horizontal layers that change from squared shape to a circular one (Figure 10). Consequently, the geometry of the typical dome is a transition between a cloister vault with imperceptible edges, in the inferior part, and a dome of revolution, in the superior part. The dome is slightly flattened: its rise is less than half of its diameter of $2.5 \mathrm{~m}$ (Figure 11). The dome is covered by a thick layer of gypsum outside, also, inside gypsum plaster is used to smooth the surface. The thickness of the domes ranges around $15-18 \mathrm{~cm}$. 

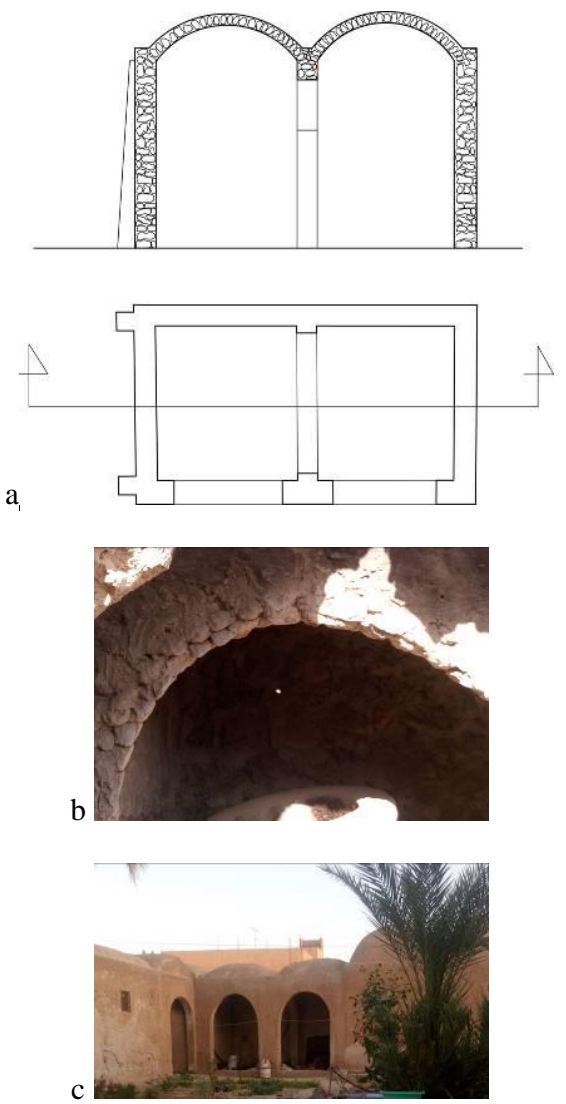

Figure 9. a. Plan-section of double domed units. b. Radial texture of the connection arch. c. Gallery with arcades.

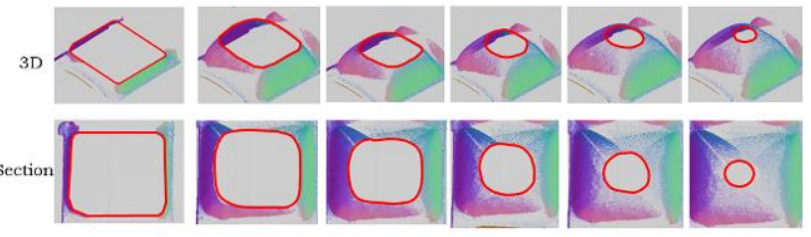

Figure 10. Sections of dome Survey 3D showing the transformations of the shape.

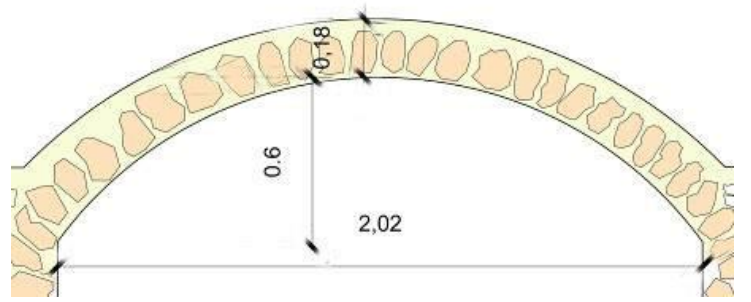

Figure 11. Section of 'Desert Rose' stone dome .

\subsubsection{Buttresses}

Buttresses are used in Souf buildings; in rural buildings, due to their dispersed distribution where they do not have a neighbouring unit which permits to counter pushes. In the city, the urban density is high and walls shared between two houses are frequent. In this case, buttresses are limited, e.g. in the exterior wall overlooking the alleys, Figure 12, and in the interior wall overlooking the courtyard.

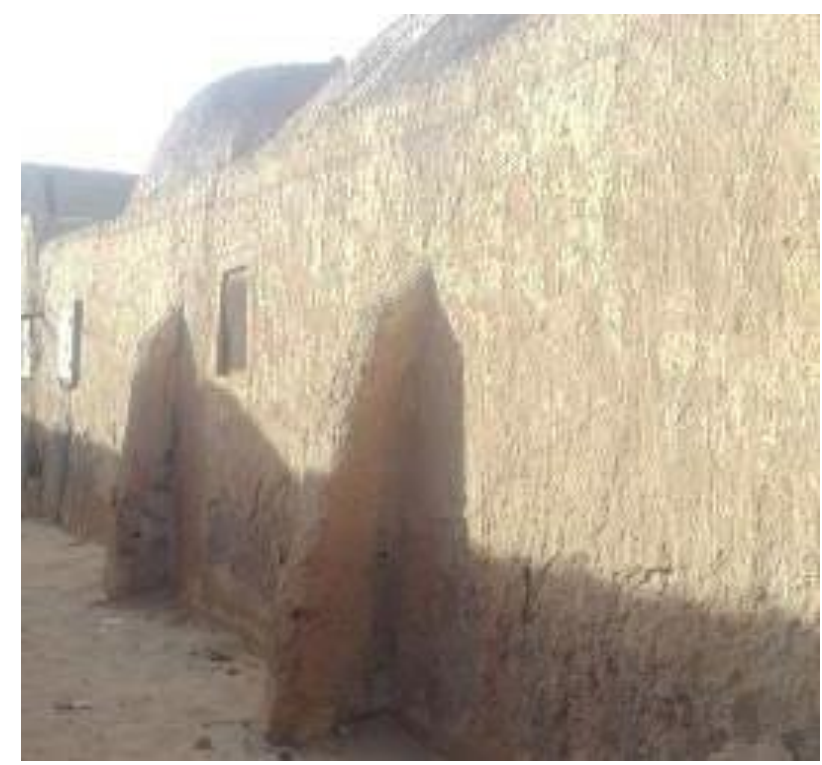

Figure 12. Buttresses of the wall overlooking the alleys.

\subsection{Mechanical characteristics of 'Desert Rose' masonry}

'Desert Rose' blocks, which are not hewn, show very irregular shape and are bonded with gypsum mortar to build masonry. The blocks are often arranged in approximately horizontal courses of different heights. Bed joints of mortar regularize the wall horizontality and smaller stone fragments push the blocks into the wall thickness acting as wedges. Stones of the upper course generally straddles two elements of the lower course in order to avoid the alignment of vertical joints. Frequently, big blocks are placed across the thickness of a wall bracing one face to the other. Because of block irregularity, the quantity of mortar used is approximately equal to stone blocks, to fill all the voids between the blocks.

Quality of masonry construction depends on several characteristics namely: properties of components (blocks and mortar), blocks shape, volumetric ratio between components, and wall texture. These characteristics vary according to the building techniques typical of the local culture. The rule of the art consists of a set of characteristics that the masonry should exhibit to ensure compactness and monolithicity to wall structure, and which should be conformed during the construction phase to provide a good mechanical behaviour.

The Masonry Quality Index (MQI) method (Borri et al, 2015), which enables to evaluate the "rule of the art" of masonries is applied here. The choice of the method is due to the complexity of the mechanical parameters identification, connected to the great number of variables; a precise estimation of mechanical properties, in theory, can be made only testing in situ the walls (Binda et al, 2000). However, it is not always possible to carry out these tests, therefore, the MQI method was chosen.

In addition to allowing an estimate of the mechanical parameters (Young' modulus, compression and shear strengths), the MQI method provides a guide to evaluate separately all the aspects influencing the mechanical behaviour of a masonry, based on qualitative observation. In fact, the MQI method represents a very useful tool to highlight the mechanical characteristics of the masonry regardless of the determination of specific parameters. 
A score constructed on experts' judgment, according to MQI method which assigns to a set of parameters identifying the rule of the art of the masonry. Based on the scores obtained for the corresponding type of actions, namely: vertical (V), in-plane (I) and out-of-plane $(\mathrm{O})$, a rank is assigned to the masonry and a range of plausible mechanical parameters can be identified. The following parameters are considered by the MQI: 1) Stone mechanical properties and conservation state (SM); 2) Stone dimension properties (SD); 3) Stone shape (SS); 4) Wall leaf connections (WC); 5) Horizontal bed joint characteristics (HJ), 6) Vertical joint characteristics (VJ); 7) Mortar mechanical properties (MM).

Compliance with the parameters of the "rule of art" is graded through three judgments: Complying (C), Partial Complying (PC), and Not Complying (NC).

The data analysis of 'Desert Rose' stone masonry are shown in Table 1. In this way, it is possible to reach a synthetic evaluation of the masonry for each types of action which the wall is subjected to. The score assigned to the "rule of art" (Borri et al., 2015), are shown in Table 02. The score obtained is summed to obtain an overall score, the Masonry Quality Index (MQI) is determined for each type of action.

For the SM parameter the judgement is Partially Fulfilled (PF) because the 'Desert Rose' stone is characterized by rather low mechanical characteristics (about $10 \mathrm{MPa}$ compression strength) with very dispersed experimental values depending on the heterogeneous nature of the material which also has a high porosity (Azil et el.2019).

Regarding the stone dimension properties SD parameter, the judgement is Partially Fulfilled (PF) for the reason that the wall is constituted of the rose desert stone with different dimensions (between 25 and $40 \mathrm{~cm}$ )

As regard stone shape SS parameter, the judgement is Not Fulfilled (NF) due to the irregularity of the blocks.

Concerning wall leaf connections WC, the judgement is Not Fulfilled (NF) because of the absence of headers.

For horizontal bed joint characteristics HJ parameter, the judgement is Not Fulfilled (NF) as result of the non-continuous horizontal bed joint.

As concern vertical joint characteristics VJ parameter; the judgement is Not Fulfilled (NF) due to the aligned vertical joints. For the mortar mechanical properties (MM) parameter, the judgement is Fulfilled (F), thanks to the large bed joint thickness made of gypsum mortar which exhibits good adhesion with block having the same mineralogical composition (gypsum).

\begin{tabular}{|c|c|c|c|c|}
\hline Parameter & Judgment & \multicolumn{3}{|c|}{ Score } \\
\hline & & V & I & O \\
\hline SM & PF & 0.7 & 0.7 & 0.7 \\
\hline SD & PF & 0.5 & 0.5 & 0.5 \\
\hline SS & NF & 0 & 0 & 0 \\
\hline WC & NF & 0 & 0 & 0 \\
\hline HJ & NF & 0 & 0 & 0 \\
\hline VJ & NF & 0 & 0 & 0 \\
\hline MM & F & 2 & 2 & 1 \\
\hline \multicolumn{2}{|c|}{ MQI index } & 1.35 & 1.35 & 1.05 \\
\hline \multicolumn{2}{|c|}{ Masonry class } & C & C & C \\
\hline
\end{tabular}

Table 1. Analysis of 'Desert Rose' stone Masonry.

\begin{tabular}{|c|c|c|c|c|c|c|c|c|c|}
\hline \multirow{2}{*}{} & \multicolumn{3}{|c|}{$\begin{array}{c}\text { Vertical } \\
\text { action (V) }\end{array}$} & \multicolumn{3}{c|}{$\begin{array}{c}\text { Horizontal } \\
\text { in-plane action (I) }\end{array}$} & \multicolumn{3}{c|}{$\begin{array}{c}\text { Horizontal } \\
\text { out-of-plane } \\
\text { action (O) }\end{array}$} \\
\cline { 2 - 11 } & NF & PF & F & NF & PF & F & NF & PF & F \\
\hline SM & 0.3 & 0.7 & 1 & 0.3 & 0.7 & 1 & 0.5 & 0.7 & 1 \\
\hline SD & 0 & 0.5 & 1 & 0 & 0.5 & 1 & 0 & 0.5 & 1 \\
\hline SS & 0 & 1.5 & 3 & 0 & 1 & 2 & 0 & 1 & 2 \\
\hline WC & 0 & 1 & 1 & 0 & 1 & 2 & 0 & 1.5 & 3 \\
\hline HJ & 0 & 1 & 2 & 0 & 0.5 & 1 & 0 & 1 & 2 \\
\hline VJ & 0 & 0.5 & 1 & 0 & 1 & 2 & 0 & 0.5 & 1 \\
\hline MM & 0 & 0.5 & 2 & 0 & 1 & 2 & 0 & 0.5 & 1 \\
\hline
\end{tabular}

Table 2. Scores table

(Borri et al, 2015).

According to the results, the masonry is categorised in C class, which has inadequate behaviour, and the mechanical characteristics are evaluated as following:

Compressive strength min and $\max (\mathrm{MPa}): \quad 1.2-2.1$

Young modulus min and max (MPa):

Shear stress min and max (MPa):

\section{LINEAR AND NONLINEAR STRUCTURAL FEM ANALYSIS}

Based on the representative model of the dome (being the most vulnerable element of the system), both linear and nonlinear structural analyses were carried out through the Finite Element Method, in order to understand the structural behaviour and identify the nature of the damage. The model was created with the commercial code DIANA FEA software. Regular curved shell element (Quad 4 \& Hex 6 elements) which are based on isoparametric degenerated-solid approach (which are characterized by both membrane and bending behaviour) with thickness of $15 \mathrm{~cm}$ were employed. The value of the elastic module inputted in the program is $810 \mathrm{MPa}$, the mean value of results obtained from the MQI. Moreover, the parameters inputted for tensile behaviour are:

1.Tensile curve: linear-ultimate crack strain

2.Tensile strength: $0.6 \mathrm{MPa}$

3.Ultimate strain: 0.005

4.Residual tensile strength: $0.01 \mathrm{MPa}$

Two model variants are created, they are differently constrained at the base so as to simulate different constraint conditions transferred by the supporting walls. The first model, model A, is basically pinned at the base. The second model, B, was provided with roller type supports, in particular each edge of the dome base can displace in the direction, but vertical and inplane displacements are not allowed. For both models, edge rotations around the direction parallel to the edge itself are allowed, while around the vertical direction and orthogonal to the edge itself are hindered. 
The principal stress contour plots of linear analyses are shown in the Figure 13 and 14. For the pinned model, A, Figure 13.a shows that that the maximum tensile stress is $6.2 \mathrm{e}-4 \mathrm{MPa}$ in the bottom part of the diagonal arches. However, in the figure14.a, the analysis of the results permitted to note that the maximum tensile stress, in the model with roller support, is $5.45 \mathrm{e}-2 \mathrm{MPa}$ in the corner.

Regarding the principal compressive stress, in the Figure 13.b of the model with pinned constrained, the results show that the values of compressive stress vary between -2.10e-2 MPa and $-2.39 \mathrm{e}-3 \mathrm{MPa}$, whereas the lower compression is in the lower part of the diagonal arches, and the highest compression is in the middle of the lower part. In the Figure 14.b of the model with roller constraints, the lower principal compression stress is $-6.97 \mathrm{e}-3 \mathrm{MPa}$, which is noted in the middle of the lower part, and the more intense compression stress is $-8.46 \mathrm{e}-2 \mathrm{MPa}$ in the corner.

Comparing the analysis results of the two variants allowed to illustrate that the variation of the results is related to constraint support type. The roller support type, provided better quality interpretation of the damage pattern surveyed.

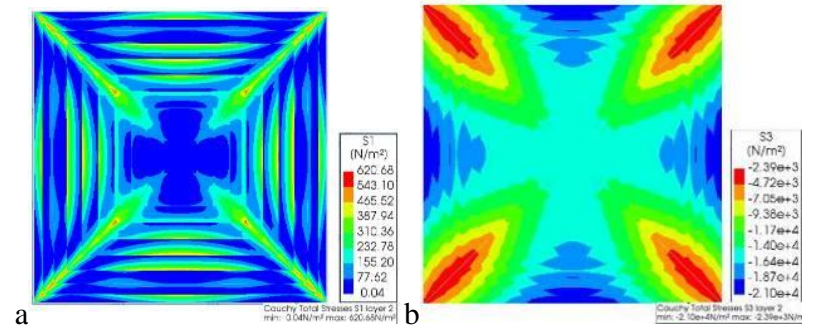

Figure 13. The main total stress results of linear analysis on the medium surface of the first model with pinned constraints: a. Tensile. b. Compression.

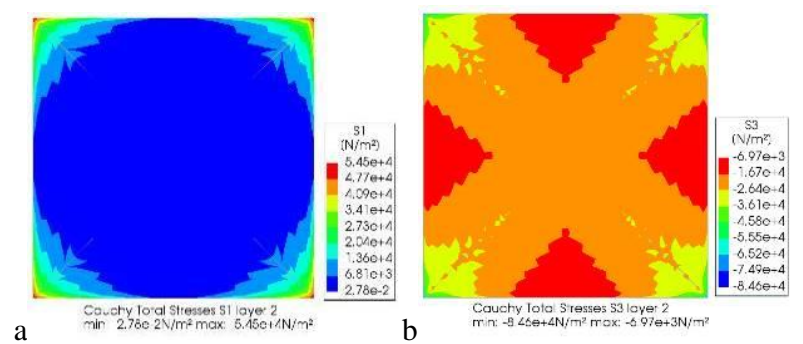

Figure 14. The principal total stress results of linear analysis on the medium surface of the second model with rolled constraints: a. Tensile. b. Compression.

The Figure 15 and 16 shows the results of crack strains of the nonlinear analysis of the two model variants namely respectively: model with pinned constraint and model with roller constraint.

In the Figure 15, in the model with pinned constraint, the crack strains in the medium surface are varied between $5.04 \mathrm{e}$ 11 and $9.36 \mathrm{e}-8$, and they are situated in two zones that are the lower part of the diagonal arches and in the top part. On another hand, in the Figure 16, in the model with roller constraint, the crack stains are varied between -2.6e-13 in the most part of the model and 3.27e- 6 in the corner diagonal arches, due the type of the constraint which allows more displacement comparing to the model with pinned constraints. Due to the higher deformability of the model constrained with rollers, which clearly reflect the damage visible in dome, only a very limited fraction of gravity acceleration can be resisted, since computation quickly diverges. The pinned model although showing a crack patter more difficult to be related to realty, can easily sustain self-weights, as actually happens. Further investigation will involve the modelling of the whole unit to provide to the dome base balanced stiffness calibrated on wall height and thickness.

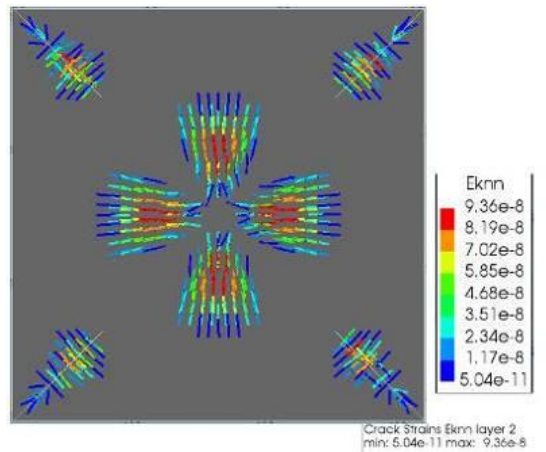

Figure 15. The crack strains result of nonlinear analysis on the medium surface of the first model with pinned constraint.

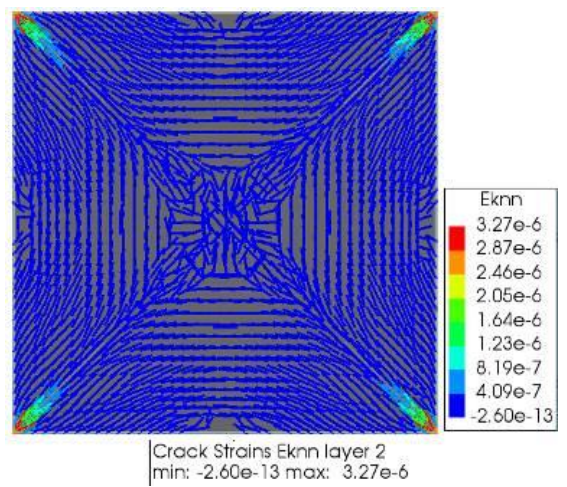

Figure 16. Crack strains distribution from nonlinear analysis, results are referred to the medium surface of the model with roller constraints.

\section{CONCLUSION}

A multidisciplinary study was carried out on the vernacular architectural heritage of the Souf region in Algeria, created with the local building materials namely 'Desert Rose' stone and the gypsum prepared from the 'Tafza' stone. The dome roofs portray a remarkable urban landscape, at the same time, they are the most vulnerable element of the structural system, showing cracks and spread collapses and devaluing this architectural heritage.

The research aims to understand the architecture and its constructive culture to safeguard this heritage.

The research carried out concern:

- The study of the Souf constructive culture: description of the geology, which constitutes the emergency factors of the Souf architectural typology, and of the preparation steps of the building materials; definition of constructive techniques and geometry of the different structural element (foundation and walls; arches and dome; buttresses). 


\begin{abstract}
- The structural and mechanical evaluation of the 'Desert Rose' masonry and the domes: estimation of mechanical parameters of masonry evaluating it according to "the rule of the art" using the Index of Masonry Quality method. The structural behaviour of a reference dome was anlyesed using a numerical simulation through the finite element method with both linear analysis, which allows to evaluate the principal stress, and static nonlinear analysis, which permits to analyse the crack strains.
\end{abstract}

The results have permitted understanding the nature of some damages which threaten this traditional construction, its structural system and materials.

The results of the quality index of masonry underline that the 'Desert Rose' masonry shows very low mechanical parameters, as a results of porosity of the material, irregularity and absence in the constructive culture of some rules of the art. Preliminary results of FEM analyses permit to understand the widespread presence of corner damages, although further refinement of the structural modelling is required.

\section{REFERENCES}

Almeida, C., Guedes, JP., Arede, A., Costa, CQ., Costa, A. 2012. Physical characterization and compression test of one leaft stone masonry walls. Construction and Building Materials (30), 97_188.

Azil, C., Djebri, B., Rovero, L., 2018. Desert rose: building material of copulas in the Souf region in Algeria, in: Sustainable Buildings and cities, Fez, Marocco (2017), IOP Conference Series.: Material Science Engineering. doi:10.1088/1757899X/353/1/012009.

Azil, C., Djebri, B., Rovero, L., 2019. Diagnosis processes for Desert Rose domes of the Souf region in Algeria, in: 2nd International Conference of Geomatics and Restoration, Milan, Italy (2019), The International Archives of the Photogrammetry, Remote Sensing and Spatial Information Sciences (XLII-2/W11, 2019).

Baglioni, E., Fratini, F., Rovero, L., 2016a. The characteristics of the earthen materials of the Drâa valley's architecture. Journal of materials \& environmental science (7), 3538-3547.

Baglioni, E., Rovero, L., Tonietti, U., 2016b. Drâa valley earthen architecture: construction techniques, pathology and intervention criteria. Journal of materials \& environmental science (7), 3499-3508.

Bataillon, C., 1955. Le Souf: Etude de géographie humaine. Unpublished $\mathrm{PhD}$ thesis. Institut de recherches sahariennes, University of Algiers, Algiers.

Binda, L., Saisi, A., Tiraboschi, A,. 2000. Investigation procedures for diagnosis of historic masonries: constructions building materials 14(4), 199-233.

Boostani, A., Fratini, F., Misseri, G., Rovero, L., Tonietti, U., 2018. A masterpiece of early Islamic architecture: The NohGonbad Mosque in Balkh, Afghanistan. Journal of cultural heritage (32), 248-256.
Borri, a., Corradi, M., Castori, G., De Maria, A., 2015. A method for the analysis and classification of historic masonry. Bulletin earthquake engineering.

Briccoli Bati, S., Ranocchiai, G. Tonietti, U., 2001. Il problema della valutazione delle proprietà meccaniche attuali e della affidabilità statica residua di elementi portanti lapidei e/o in calcestruzzo armato. In: Proceedings of the national congress, Crolli e affidabilità delle strutture civili, Venezia, Italia.

Cote, M., 2005.La ville et le désert: Le Bas-Sahara algérien, Karthala, Paris.

Cote, M., 2006. Si le Souf m'était conté: Comment se fait et se défait un paysage. Média-Plus, Constantine.

Lebsir, A., 2016. Les cultures constructives traditionnelles architecture: Cas des Aurès, L'Oued Mya et Le Souf, Unpublished $\mathrm{PhD}$ thesis, Mohamed Khider university, Biskra.

Liberotti, G., Rovero, L., Stipo, G., Tonietti, U., 2016 Mechanical investigation on adobe samples belonging to the archaeological site of Arslantepe (Malatya, Turkey). Journal of materials and environmental science 7, 3656-3666.

Rovero, L., Alecci, V., Mechelli, J., Tonietti, U., De Stefano, M., 2016. Masonry walls with irregular texture of L'Aquila (Italy) seismic area: validation of a method for the evaluation of masonry quality. Materials and Structures (49), 2297-2314.

Rovero, L., Fratini, F., 2013. The Medina of Chefchaouen (Morocco): A survey on morphological and mechanical features of the masonries. Construction and Building Materials (47), 465-479.

Rovero, L., Tonietti, U., 2012. Structural behaviour of earthencorbelled domes the Aleppo's region, Materials and Structures 45, 171-184.

Rovero, L., Tonietti, U., Fratini, F., Rescic, S., 2009. The salt architecture in Siwa oasis - Egypt (XII-XX centuries). Construction and Building Materials 23 (7), 2492-2503

Sani, F., Moratti, G., Coli, M., Laureano, P., Rovero, L., Tonietti, U., Coli, N., 2012 Integrated geological-architectural pilot study of the Biet Gabriel-Rufael rock hewn church in Lalibela, northern Ethiopia. Italian Journal of Geosciences 131 (2), 171-186.

https://dzcharikati.net/el-oued-la-phoeniciculture-dans-le-ghoutun-patrimoine-agricole-et-touristique/ , accesses on 20/01/2020. 